\title{
Population size and structure of whale sharks Rhincodon typus at Ningaloo Reef, Western Australia
}

\author{
Mark G. Meekan ${ }^{1, *}$, Corey J. A. Bradshaw ${ }^{2}$, Michelle Press ${ }^{3}$, Cary McLean ${ }^{4}$, \\ Allison Richards ${ }^{5}$, Suzy Quasnichka ${ }^{6}$, J. Geoff Taylor ${ }^{7}$ \\ ${ }^{1}$ Australian Institute of Marine Science, PO Box 40197, Casuarina MC, Northern Territory 0811, Australia \\ ${ }^{2}$ School for Environmental Research, Institute of Advanced Studies, Charles Darwin University, Darwin, \\ Northern Territory 0909, Australia \\ ${ }^{3}$ School of Science and Primary Industries, Charles Darwin University, Darwin, Northern Territory 0909, Australia \\ ${ }^{4}$ Australian Institute of Marine Science, PMB 3, Townsville MC, Queensland 4810, Australia \\ ${ }^{5}$ PO Box 293, Exmouth, Western Australia 6707, Australia \\ ${ }^{6}$ Iambic Productions, 89 Whiteladies Road, Clifton BS8 2NT, UK \\ ${ }^{7}$ PO Box 126, Busselton, Western Australia 6280, Australia
}

\begin{abstract}
We used photo-identification to produce estimates of population size and structure of whale sharks Rhincodon typus at Ningaloo Reef, Western Australia. We analysed photographs of whale sharks taken from 1992 to 2004 . A combination of spot and stripe patterns behind the last gill slit and forward of the dorsal fin (lateral view), and distinctive scars and marks on the body and fins were useful for identifying individual sharks. These patterns appeared to be unique to individuals and distinctive markings could be recognized on some sharks for more than a decade. From 581 photographs, 159 individuals were identified. Of these, $74 \%$ were male, $16 \%$ were female and $10 \%$ were of indeterminate gender. Photographed sharks ranged in estimated size from 3 to $10 \mathrm{~m}$ total length (TL). The size distribution of sharks was bimodal with a large peak at $8 \mathrm{~m}$ and a smaller peak at $6 \mathrm{~m}$ TL. Sixty individuals were resighted during the study. Of these, 46 were resighted at different times during the same year (sometimes on multiple occasions) up to 4 mo after they were initially photographed, and 33 were resighted ( 4 on $>2$ occasions) in different years. The interval between inter-annual resightings was typically 1 to 3 yr; however, 2 sharks were resighted after a period of $12 \mathrm{yr}$. We estimated the super population of whale sharks that visit Ningaloo Reef to consist of approximately 300 to 500 individuals (95\% confidence interval) based on closed population models, or 320 to 440 based on Jolly-Seber open-population models. Our study shows that photo-identification offers a practical, non-invasive and non-destructive means to obtain data on the population size and demography of whale sharks.
\end{abstract}

KEY WORDS: Abundance · Cormack-Jolly-Seber models · Lincoln-Peterson estimator · Markrecapture models $\cdot$ Photo-identification $\cdot$ Program MARK $\cdot$ Sex ratio $\cdot$ Whale shark

Resale or republication not permitted without written consent of the publisher

\section{INTRODUCTION}

The world's largest fish, the whale shark Rhincodon typus, is also one of the least-known shark species. At present even basic information such as population size, structure and demography of these animals is lacking. Whale sharks inhabit tropical waters worldwide (Colman 1997), and at a few localities, predictable aggregations occur where they support lucrative eco-tourism (snorkelling and diving) industries. In other locations, whale shark aggregations are fished to supply meat to Taiwan and fins to markets throughout Southeast Asia. The growing affluence of Asia has led to an increasing demand for whale shark products, stimulating effort in traditional fisheries and the development of new fisheries in places such as India during the 1990s (CITES 2002). Although many countries, including India, have now implemented legislation that forbids their capture, 
catch statistics and anecdotal reports suggest that the status of whale shark population throughout the IndoPacific is declining (CITES 2002).

It is unlikely that whale sharks can tolerate intensive fishing pressure because they are thought to share the typical elasmobranch life-history patterns of slow growth and late maturity (Colman 1997). Whale sharks may not reach sexual maturity until 35 to $50 \mathrm{yr}$ of age and may live to 100 yr based on conservative estimates (Colman 1997, Wintner 2000). If these estimates are correct, population reduction due to over fishing is likely and recovery will be slow. Additionally, recent studies have shown that the species is highly migratory, with some individuals travelling thousands of kilometres across oceans (Eckert et al. 2002). The effects of over fishing in one part of the species range may thus be manifested in populations at other localities where the animals are protected from exploitation.

To determine the conservation status of whale sharks and to maintain the ecotourism industries that these animals support, basic information on the population size and life-history traits is urgently required. This is difficult to obtain from fishery data due to rapidly declining catches and the illegality of the shark harvest in many countries (CITES 2002). However, markrecapture studies provide an alternative, nondestructive means to generate estimates of these parameters (Lebreton et al. 1992, Nichols 1992). Such techniques require the identification of individuals within a population so that they can be recognized when recaptured or resighted at a later date. Generally, this is done by capturing a study animal and attaching or inserting a tag for individual identification. In the case of whale sharks, it is logistically impossible to restrain study animals and in many countries there are ethical or legal restrictions that forbid this treatment. Tags have been attached to unrestrained animals using pole spears; however, rates of tag retention are often low, making this method unsuitable for long-term ( $\geq 1 \mathrm{yr}$ ) studies (D. Rowat pers. comm.).

Photo-identification techniques have been used to overcome similar problems in mark-recapture studies of other marine fauna such as cetaceans (reviewed by Würsig \& Jefferson 1990). In this approach, photographs are taken of distinctive parts of an animal (often the shape of trailing edges and pigmentation of fins) that permit individual identification when observed again. This technique has been used to generate estimates of population size, movement patterns, group structure, and demographic variables such as age at sexual maturity, life span and survival rates for many marine species (Hamilton et al. 1998, Chaloupka et al. 1999, Forcada et al. 1999, Stevick et al. 2001, Kendall et al. 2003, Mizroch et al. 2004, Castro \& Rosa 2005). Additionally, data concerning growth rates have also been collected with photo-identification through the use of photo-grammetry (Koski et al. 1992). This involves measuring the animal with either stereophotography or photographing objects such as divers at a known height and a distance from the animal (Würsig \& Jefferson 1990).

Here, we examine the use of photo-identification as a means to estimate population size and structure of whale sharks at Ningaloo Reef, Western Australia. Whale sharks aggregate predictably at this locality from March to June each year (Taylor 1996, Wilson et al. 2001), a phenomenon that is the basis of an ecotourism industry of great importance to the local economy of the region (Davis et al. 1997, Davis 1998). Observers have taken photographs of individual sharks participating in the aggregation for the last 12 yr (1992 to 1996, 2002 to 2004) and these photographs now form a library for photo-identification studies.

\section{MATERIALS AND METHODS}

Photographs and measurements. A total of 581 photographs were taken of whale sharks between March and July from 1992 to 2004 by the authors and various ecotourism operators. Photographs were taken using an underwater still camera or digital video camera while snorkelling with the animal. Still images of sharks were captured from videotape for analysis. Total length (TL-tip of snout to end of caudal fin) and dorsal fin height (DFH) were recorded using a measuring tape after animals were photographed. The sizes of animals photographed from ecotourism operations in 2004 were estimated based on the known lengths of snorkelers swimming alongside animals. In a few cases these size estimates were validated using a tape measure.

To convert measurements of DFH to TL, we calculated a least-squares linear regression (TL $=a+b \times$ $\mathrm{DFH})$ to provide a predictive equation and used the $\mathrm{r}^{2}$ as a measure of the model's structural goodness-of-fit. We examined the evidence for a linear relationship between TL and DFH based on Akaike's Information Criterion (Akaike 1973) corrected for small sample size $\left(\mathrm{AIC}_{C}\right)$ (Lebreton et al. 1992). The information-theoretic evidence ratio $(E R$, an index of the likelihood of one model over another, calculated as the $\mathrm{AIC}_{C}$ weight $(w)$ of the slope model/ $w$ of the null model) (Burnham \& Anderson 2002) was then calculated to examine the relative statistical support of the relationship. During 1992, no DFHs were measured and no TLs were recorded.

Whenever possible, observers recorded the gender of the animal. Males could be distinguished easily by 
the presence of claspers on the pelvic fins (Taylor 1994). Claspers may be difficult to discern in relatively small sharks $(<4 \mathrm{~m}$ TL), so those animals were recorded as indeterminate gender. In some cases, sharks dived or swam away before gender could be determined, so those individuals were also included in the indeterminate category. All known-sex animals for which a TL estimate was available were assigned to 1 of 2 size classes: 'small' if TL $\leq$ mean TL or 'large' if TL > mean TL to examine temporal trends in size-class distribution. The null hypotheses testing frequency differences among classes (e.g. sex, size) and over time (e.g. years) were tested using the G-test of independence with William's correction for small sample sizes (Sokal \& Rohlf 1981).

Identifying marks. Whale sharks have characteristic patterns of white spots and stripes on the dark background of their dorsal surface (Fig. 1). Examination of photographs of the dorsal surface showed that patterns in spots and stripes ranged from complex (and thus distinctive) whirls and shapes, to relatively simple lines (and thus less distinctive). To compare patterns among sharks we focused on patterns in an area of the lateral surface directly behind the last gill slit forward of the dorsal fin. This area was chosen for analysis because it could be defined easily and consistently for inter-animal comparisons and importantly, because it appeared in a large number of photographs.

Many sharks also had scars on their body surface or fins (Fig. 2). These were often distinctive and appeared to be formed either by boat strike (rows of parallel scars along the dorsal surface, as might be expected from impact with the propeller of a large vessel) or by bites (circular portions removed from fins). Our observations indicate that large, fresh bite wounds take approximately 1 yr to heal completely (Fitzpatrick et al. 2006). Where photographs included views of these markings, they were also used for identification of individuals.

Comparison of photographs. All photographs were divided into smaller groups for analysis on the basis of distinctive scars (Fig. 2) or markings and gender. Because there were a relatively small number of photographs, comparisons of marking patterns and scars among photographs were made with the naked eye (although other automated methods exist and would be practical for larger datasets, e.g. Arzou- manian et al. 2005). Prior to analysis, hard copies of photographs were printed. Only photographs that showed the lateral area behind the last gill slit to the dorsal fin and were of good overall quality were analysed. Photographs were cropped, grey-scaled and the brightness and contrast adjusted before comparisons were made. All photographs were analysed by a single observer (M.P.). A subset of the photographs (1992 to 1996) was also analysed independently by a second observer (J.G.T.). Matches of sharks for the entire database were independently verified by a third observer (M.G.M.).

One potential problem was the possibility of classing an individual shark as 2 separate individuals when only one side of the animal had been photographed. This would give rise to the potential for double-counting individuals and artificially increasing the size of the
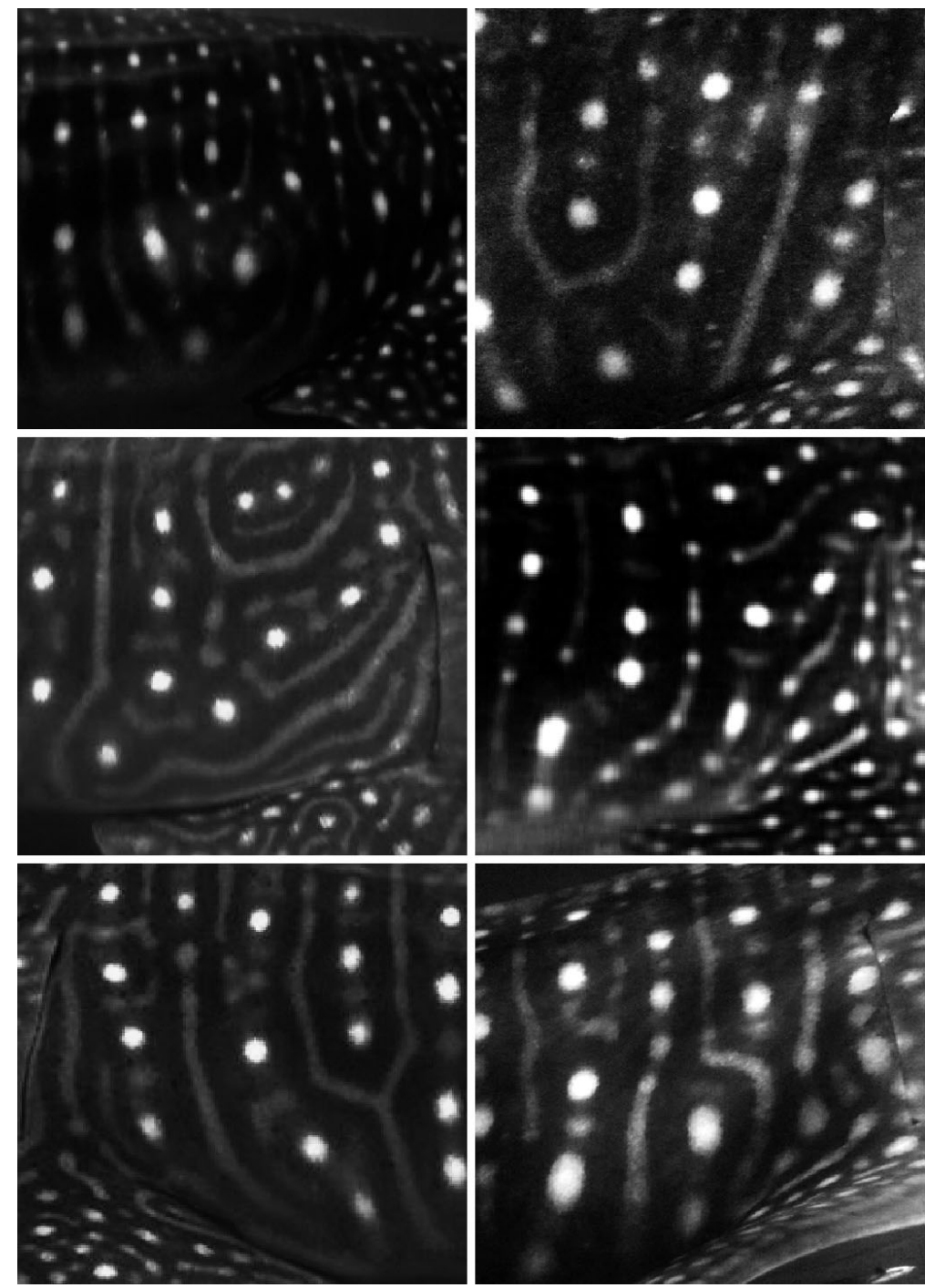

Fig. 1. Distinguishing patterns of spots and stripes on the dorsal surface behind the last gill slit of whale sharks at Ningaloo Reef 

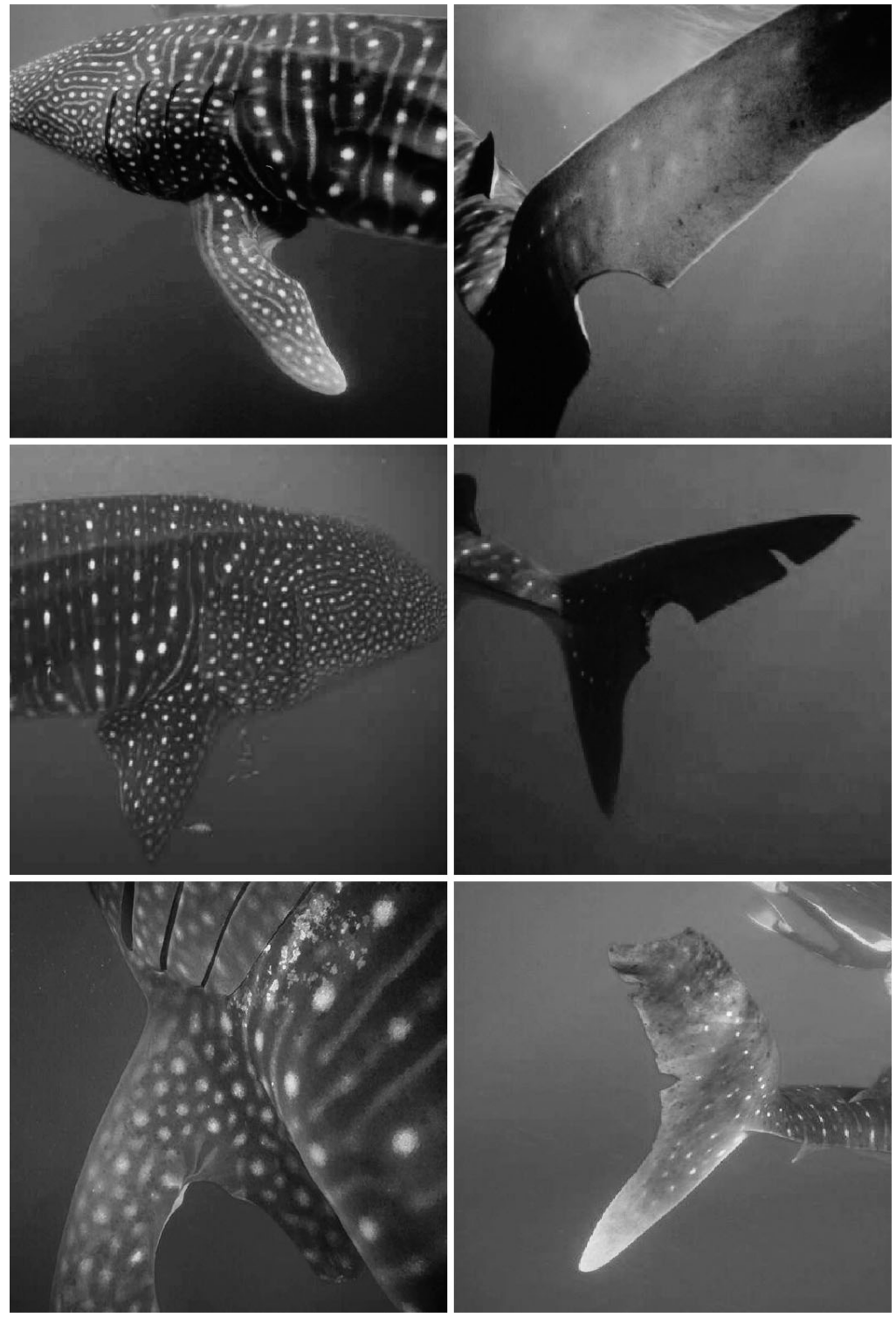

Fig. 2. Scars on fins of whale sharks at Ningaloo Reef

estimates $(\hat{N})$. For closed population models, we used the program CAPTURE (Otis et al. 1978) to examine variants of the basic Lincoln-Petersen (LP) model:

$$
\hat{N}=\frac{n_{1} n_{2}}{m_{2}}
$$

where $n_{1}=$ initial sample of marked animals, $n_{2}=$ subsequent sample of individuals from the same population and $m_{2}$ = the number of $n_{2}$ animals with marks. The models considered relax the assumption of equal probability of capture among individuals due to: heterogeneity among (unspecified) groups $\left(\mathrm{M}_{h}\right)$, variation among sampling occasions $\left(\mathrm{M}_{t}\right)$ and behavioural responses to 'capture' $\left(\mathrm{M}_{b}\right)$. The time-variant models assume that for $t$ capture occasions there are $t$ possible capture probabilities. The estimators used for the different models included Darroch's maximum likelihood for time-variant capture probabilities (Darroch 1958, Otis et al. 1978), Chao's time-variant capture probability (Chao 1989), individual heterogeneity (Chao 1989) and a time- and individual-variant capture probability model (Chao et al. 1992). The Chao estimator is particularly useful when the probability of capture is small (as in this study). Readers are directed to the original literature for more detailed information because the estimators are complex numerical functions without simple open-form solutions (Cerchio 1998). Program CAPTURE provides goodness-of-fit tests for each model and a model-selection procedure to identify the most probable model(s) (Otis et al. 1978). Model selection is based on a multivariate discriminant

database. Fortunately, most of the individuals in the database were photographed on both flanks so that they could be classed as a single individual (see 'Results'). Some individuals that were photographed on only one side also displayed characteristic marks or scars that removed the possibility of double counting. For those individuals only ever photographed on one flank without accompanying scars, we chose the flank with the highest occurrence of photographs and rejected the remaining side to avoid double counting (see 'Results').

Population size. We used a series of mark-recapture models that either assume demographic closure (no net immigration or emigration) or not to generate abundance function analysis where 7 different closed-population models are compared using selection criteria derived from goodness-of-fit significance tests. The most-likely model is the one corresponding to the maximum selection criterion (see Otis et al. 1978 for more detail).

After removing photographs of insufficient quality, there were none available for 2002, so this year was removed from the analysis. We modelled all remaining years (1992 to 1996, 2003 to 2004) together using the closed-population approach; however, due to the inconsistent temporal series of photographs available (see 'Results'), we repeated the above analyses with data from 1992 to 1996 only ( $t=5 \mathrm{yr}$ ). Thus, by examining the different temporal series separately, a better inter- 
pretation of the assumption of demographic closure could be made.

The assumption of demographic closure tests the null hypothesis that the capture probability of individual $i$ $\left(p_{i}\right)$ is invariant at each sampling occasion. The alternative hypothesis is that some individuals have $p=0$ at the beginning or end of the study period (Otis et al. 1978, Cerchio 1998). Thus, the test is not sensitive to temporary emigration and can demonstrate low power when recaptures are low (Otis et al. 1978). Therefore, we applied an open-population Jolly-Seber model (Schwarz \& Arnason 1996) to the mark-recapture data using the POPAN option in the program MARK (White $\&$ Burnham 1999) to estimate population size. For $t$ capture occasions the model provides $t-1$ estimates of $\phi$ (apparent survival), $t$ estimates of $\mathrm{p}$ (capture probability given the animal is alive and available for capture), $t-1$ estimates of $\beta$ (probability of entry into the population per occasion), and $N$ (super-population size). Models were fitted using the logit link function for $\hat{\phi}$ and $\hat{p}$, the

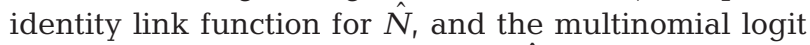
link function to constrain the set of $\hat{\beta}$ parameters to $\leq 1$ (otherwise, convergence can be problematic, White \& Burnham 1999). The number of parameters for each model was adjusted to account for parameters not estimable due to low recovery rates in certain years. We used Akaike's Information Criterion corrected for small sample sizes $\left(\mathrm{AIC}_{c}\right)$ to compare models and provide model-averaged estimates of $N$ (Burnham \& Anderson 2002). Estimates of $\phi, p$ and $\beta$ were not developed under the full Cormack-Jolly-Seber (White \& Burnham 1999) mark-capture framework (because estimating these parameters was not a central aim of the study) and so are not reported here.

\section{RESULTS}

\section{Photograph quality}

Problems of poor focus and reflected light on the lateral surface on the animal made it difficult to discern spot and line patterns and resulted in the rejection of many photographs for identification. In total, poor clarity or incorrect angle and composition led to the rejection of $28 \%$ (163) of the photographs prior to analysis. Up to $80 \%$ of the photographs taken by an observer with 20 yr experience in underwater photography could be analysed, while only $50 \%$ of photographs taken by an observer with a few months of experience were of sufficient quality for analysis. Furthermore, we rejected $68 \%$ of images collected by underwater video camera due to graininess and poor image quality. This left a total of 221 images (62\%) available for analysis.

\section{Photo-identification using distinctive markings and scars}

Scars on the body or fins aided individual identification. A total of 12 individuals displayed some type of distinctive scar that was consistent with either a boat strike or a bite from another animal. Of these, 3 showed evidence of a boat strike and 8 displayed scars from bite marks. Using a combination of scars and stripe and spot patterns, 2 sharks that were first photographed in 1992 were recognised in photographs taken in 2004 (Fig. 3). These patterns therefore appear to remain unchanged for a decade or more in these animals.

\section{Population structure}

Once repeated photographs of the same individuals were removed, the databases revealed that a total of 184 sharks were photographed between 1996 and 2004. Of these, 113 individuals were photographed on both sides, 8 were photographed on one side only but had accompanying marks or scars, and 4 were identi-

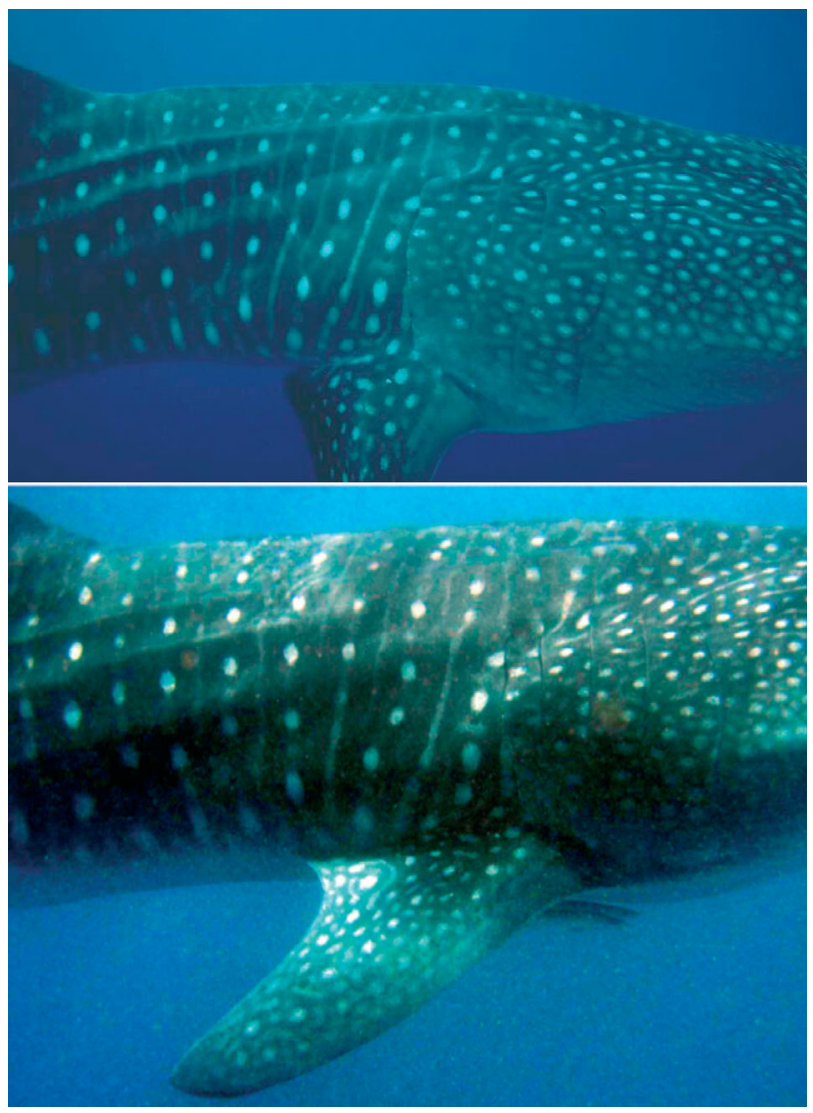

Fig. 3. Photograph of the same whale shark taken at Ningaloo Reef in 1992 (upper panel) and 2004 (lower panel) 
fied solely from characteristic marks. Another 59 individuals were photographed only one side but did not have accompanying records of characteristic marks (25 on the left side only, 34 on the right side only). For the estimation of population size we therefore chose to omit the 25 sharks that had left-side only photographs, thus giving a total number of 159 known individuals (i.e. without the potential for double counting).

Of these 159 individuals, 118 (74\%) were male, 25 $(16 \%)$ were female and $16(10 \%)$ were of indeterminate sex. There was evidence for a change in the relative proportions of males, females and animals of indeterminate gender photographed in each year of the study $\left(G_{4}=17.31, \mathrm{p}=0.002\right.$, pooling $1992 \&$ \& 1993, and $2003 \& 2004)$, and evidence for a change in the female:male proportion over time $\left(G_{4}=9.38, \mathrm{p}=0.052\right.$, pooling 1992 \& 1993, and 2003 \& 2004) driven by a relative increase in females in 1994 and 1995 (Fig. 4A). Trends of gender composition were examined among months during 2004 (Fig. 4B). The majority of sharks were photographed from April to June and there was no evidence for a change in sex ratio among months $\left(G_{2}=2.52, \mathrm{p}=0.283\right.$, pooling Mar-Apr and Jun-Jul). Male sharks predominated in all months.

There was a strong linear relationship between TL and DFH for the 31 individuals where both DFH and TL were measured for the same animal $\left(r^{2}=0.83\right)$, such that the positive slope model was $3.84 \times 10^{11}$ (ER) times more likely than the null model (Fig. 5). Therefore, we constructed this linear model to predict TL based on $\mathrm{DFH}(\mathrm{TL}=10.3484 \times \mathrm{DFH}+1.0587$, where $\mathrm{DFH}$ and TL are measured in metres) for the additional 53 individuals that had no direct measurement of TL. This dataset, combined with those sharks for which TL had been measured directly, provided a total of 128 sharks with a measured or estimated total length. Mean total length was $6.7 \mathrm{~m}$ and ranged from 3.0 to $9.7 \mathrm{~m}$ (the largest animal was a male). The size distribution was

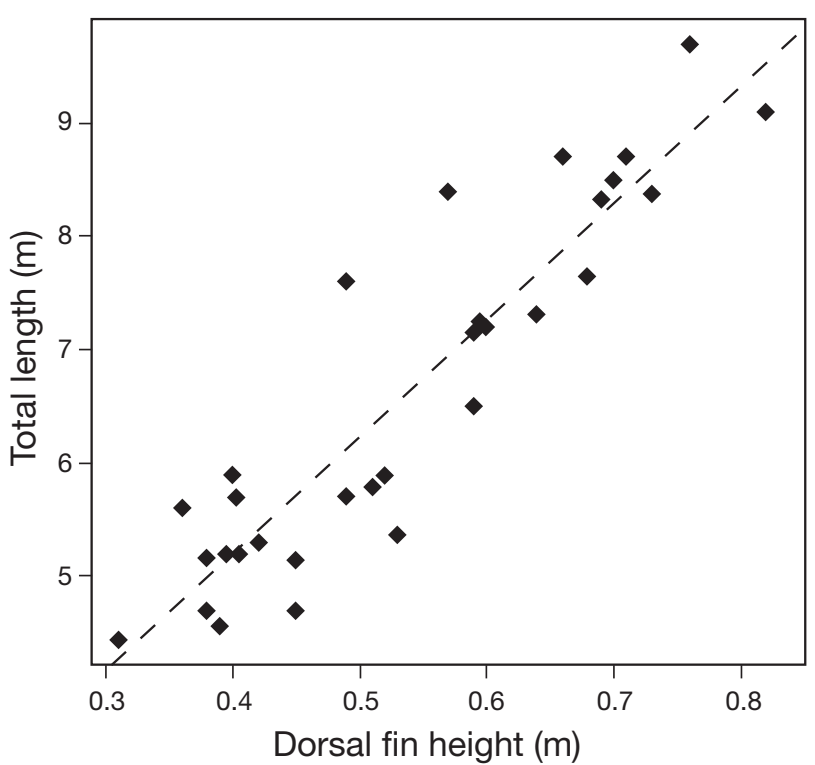

Fig. 5. Dorsal fin height vs. total length of whale sharks measured at Ningaloo Reef

bimodal with the largest peak in numbers occurring at $8 \mathrm{~m}$ TL and a smaller second peak in abundance at $6 \mathrm{~m}$ TL (Fig. 6A). Male whale sharks averaged $6.8 \mathrm{~m}$, and females averaged $6.3 \mathrm{~m}$ TL. There was evidence for differences in the size distribution of individuals among years $\left(G_{3}=28.7, \mathrm{p}<0.001\right.$, pooling $1993 \& 1994$ and $2003 \& 2004$ ) driven by an increasing frequency of small individuals seen in recent years (Fig. 6B).

\section{Resightings of individually identified sharks}

The analyses of shark resights for the photographs taken between 1992 and 1996 indicated a total of only 2 resights out of 60 (i.e. $3 \%$ ) that were missed in the first assessment. Therefore, we are confident that our rate of loss for marks is low (but see 'Discussion' for caveats concerning this
B

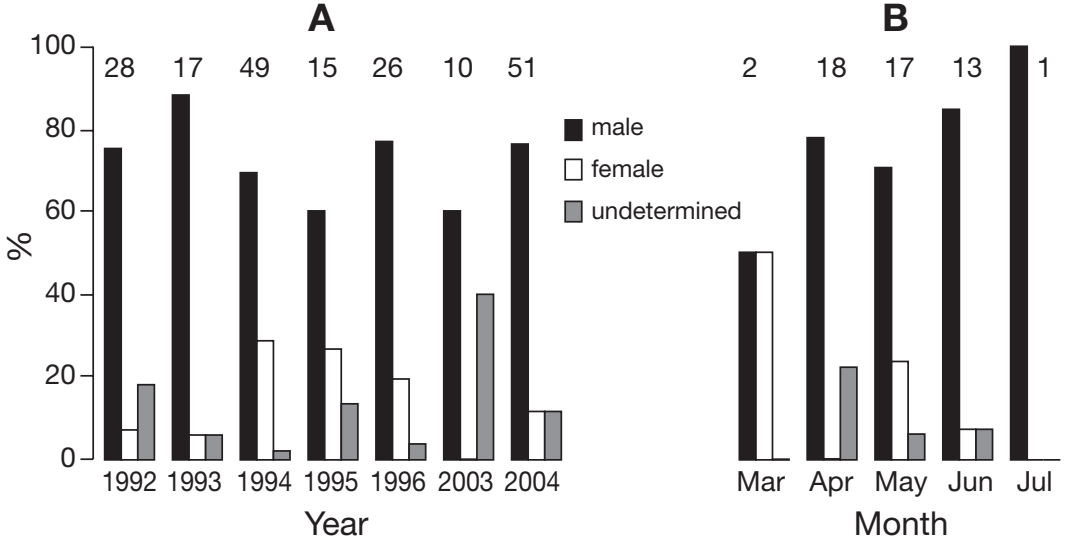

Fig. 4. Percentage of whale sharks photographed by gender by (A) year and (B) month from March-July 2004. Numbers above bars indicate sample sizes assumption). A total of 60 individuals were resighted either within the same year or between years from 1992 to 2004. Overall, $73 \%$ of the resighted sharks were male, $17 \%$ were female and $10 \%$ were of indeterminate sex. At different times during the same year of initial identification 46 sharks were resighted (sometimes more than once), and 33 individuals were resighted in different years. Within the same year, 30 sharks were photographed at least twice, 16 sharks were photographed on 3 separate occasions and 5 sharks were photographed from 4 to 7 times. Intervals between resights of the same sharks in 

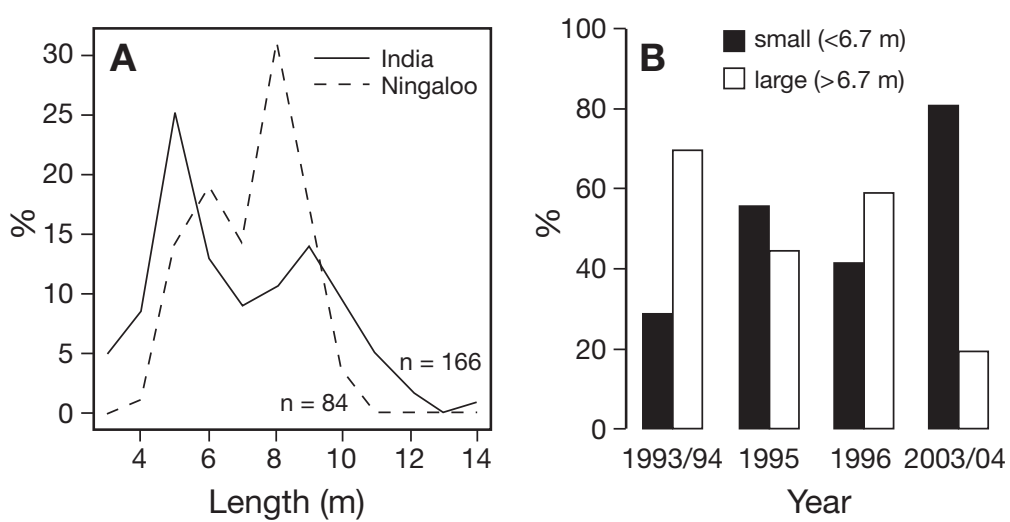

Fig. 6. Size-frequency distributions of whale sharks: (A) harvested in India between 1990-1998 (after Pravin 2000) and photographed between 1992-2004, (B) and at Ningaloo Reef for 4 periods

different years averaged $2.7 \mathrm{yr}$ (median = 2) and ranged from 1 to 11 yr (Fig. 7), with the longest maximum interval between sightings (i.e. ignoring successive sightings within that interval) was 12 yr. Most of the sharks resighted in subsequent years were first photographed in 1992.

\section{Population size}

A total of 7 'capture' sessions (excluding 2002) with 159 individuals photographed (196 separate sightings) over the study period, generated a series of population estimates under the different models and estimators tested. Using the model selection criteria provided by CAPTURE, the time-variant model $\left(\mathrm{M}_{t}\right)$ provided the

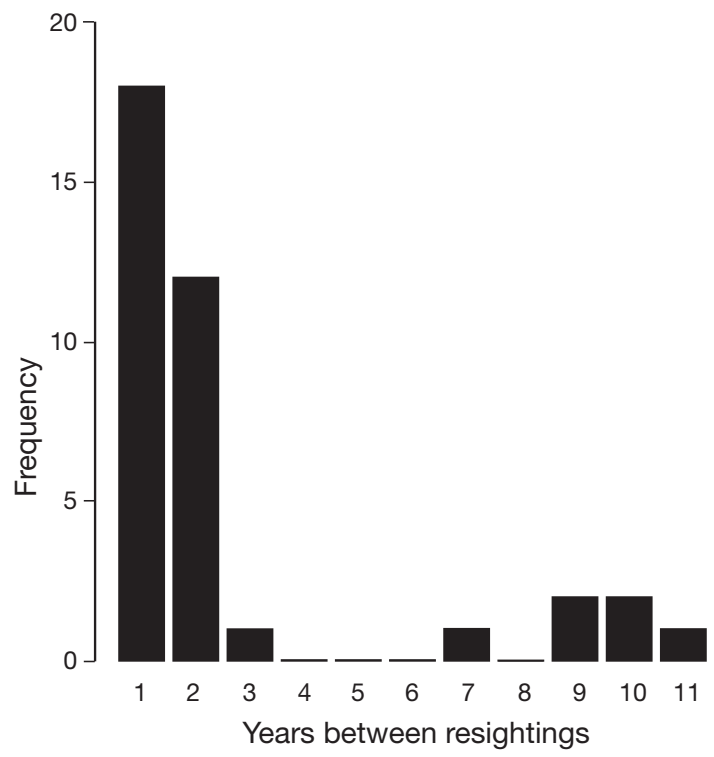

Fig. 7. Frequency distributions of inter-annual resightings of whale sharks identified from photographs taken at Ningaloo Reef best fit $\left(\chi_{66}^{2}=58.5, p=0.74\right.$, model selection criterion $=1.0$ ), followed by some support for the time-variant and heterogeneity model $\left(\mathrm{M}_{t h}\right.$, model selection criterion $=0.62$ ). Population estimates from all models are summarized in Table 1. The $\mathrm{M}_{t}$ model using the Darroch estimator provided time-variant capture probabilities $\left(p_{t}\right)$ ranging from 0.03 (2003) to 0.13 (1994 $\& 2004)$, with no trend over time. The test for closure indicated that the assumption was not violated $(z=-0.691, p=0.24)$ under the null model of no heterogeneity in capture probabilities. However, the test for closure by frequency of capture indicated violation of this assumption $(z=-3.529, p=0.0002)$. Using only 5 'capture' sessions from 1992 to 1996, model selection again revealed the $\mathrm{M}_{t}$ model as having the best fit $\left(\chi_{27}^{2}=24.0, p=0.63\right)$. However, abundance estimates were considerably lower (Table 1), with $p_{t}$ ranging from 0.07 (1995) to 0.25 (1994; Darroch), and 0.08 (1995) to 0.28 (1994; Chao), with no trend over time.

Using the POPAN open-population Jolly-Seber model structure implemented in MARK for 1992 to 2004, only 1 of the time-variant models for apparent survival $(\phi)$, capture probability (p) and the probability of entry in the population $(\beta)$ converged due to low recovery rates in some years, the model with time-variant $\beta(\hat{\phi}[.] \hat{\mathrm{p}}[.] \hat{\beta}[t] \hat{N}[]$.$) . This model demonstrated an$ information-theoretic support ( $\mathrm{AIC}_{C}$ weight) of approximately $100 \%$, and provided a super-population size of 319 to 436 (Table 1). A $\chi^{2}$ goodness-of-fit test indicated that this model fit the data reasonably well $\left(\chi_{1}^{2}=1.69\right.$, $\mathrm{p}=0.19$, Table 1). Examining the data from 1992 to 1996, only the null model $(\hat{\phi}[.] \hat{p}[.] \hat{\beta}[.] \hat{N}[]$.$) converged,$ providing a super-population size of 193 to 341 for that time period (Table 1).

\section{DISCUSSION}

Our study demonstrates that photo-identification can be used to recognize individual whale sharks of the Ningaloo Reef aggregation. Many individuals also bore distinctive scars on the fins or dorsal surface that aided identification and could be used to confirm recognition based on spot and stripe markings. Patterns in spot and stripe markings appeared to be unique to each individual because the same pattern was not found on more than one shark (Arzoumanian et al. 2005). We were able to identify 159 whale sharks successfully using this method. Approximately $74 \%$ of these were male, a pattern that was consistent both within and among years. The observation of a male bias supports Taylor's (1994) suggestion that the aggre- 
Table 1. Summary of population size estimates from closed- and openpopulation models

\begin{tabular}{|c|c|c|c|c|c|}
\hline \multirow[t]{2}{*}{ Model } & & \multicolumn{2}{|c|}{ Goodness-of-fit } & \multirow{2}{*}{$\begin{array}{c}\hat{N} \\
\text { range }\end{array}$} & \multirow{2}{*}{$\begin{array}{l}\mathrm{CV} \\
(\%)\end{array}$} \\
\hline & & $\chi^{2}$ & $\mathrm{p}$ & & \\
\hline \multicolumn{6}{|l|}{ Closed } \\
\hline \multicolumn{6}{|l|}{$\mathrm{M}_{t}(1992-2004)$} \\
\hline & Chao & $\chi_{66}^{2}=58.5$ & & $278-490$ & 14.8 \\
\hline & Darroch & & 0.74 & $300-497$ & 13.1 \\
\hline \multirow{3}{*}{$\begin{array}{l}\mathrm{M}_{t h}(1992-2004) \\
\mathrm{M}_{t}(1992-1996)\end{array}$} & & & & $301-589$ & 17.6 \\
\hline & Chao & $\gamma^{2}=240$ & & $146-248$ & 139 \\
\hline & Darroch & & 0.63 & $158-259$ & 13.0 \\
\hline \multicolumn{6}{|c|}{ Open (Jolly-Seber) } \\
\hline $1992-2004$ & & $\chi_{1}^{2}=1.69$ & 0.19 & $319-436$ & 8.0 \\
\hline 1992-1996 & & $\chi_{1}^{2}=1.40$ & 0.24 & $193-341$ & 14.8 \\
\hline
\end{tabular}

gation of whale sharks at Ningaloo is dominated by males. Although information on the composition of populations at other aggregation sites is limited (Colman 1997), sexual segregation or biased sex ratios appear to be a general characteristic of shark populations (Springer 1967, Klimley 1987). Segregation is also known to occur in other large planktivorous sharks (e.g. basking sharks Cetorhinus maximus) where animals occur in groups of similar size (Wilson 2004). Segregation or biased sex ratios are thought to result from intra-specific competition for food or mates, or through reproductive strategies associated with mating behaviour or via differing seasonal habitat or resource requirements (Sims et al. 2001). Biased sex ratios may also indicate differential mortality rates (Heithaus 2001) or different migration patterns (Pratt 1979).

Whale sharks photographed at Ningaloo Reef ranged from 3 to $10 \mathrm{~m}$ in estimated total length. This size range appears typical of other aggregation sites. For example, whale sharks captured in India's coastal fishery from 1990 to 1998 ranged between 3 and $12 \mathrm{~m}$ TL (Fig. 6A, Pravin 2000). At both India and Ningaloo, size distributions were bimodal, with peaks occurring at around 5 to $6 \mathrm{~m}$ and at 8 to $9 \mathrm{~m}$ (Fig. 6A). The largest animal recorded from our dataset was a male estimated at 9.7 m TL. Despite its size, this is a relatively small individual compared to the reports of a whale shark landed in Taiwan in 1987 that weighed $34 \mathrm{t}$ and reputedly measured $20 \mathrm{~m}$ TL (Chen et al. 1997). Size at maturity of whale sharks is thought to be around 8 to $9 \mathrm{~m} \mathrm{TL}$ (Colman 1997), although this is based on few reliable data. This implies that nearly all of the sharks aggregating at Ningaloo Reef are sexually immature as suggested by Taylor (1996). The increasing frequency of smaller individuals found in our study may also indicate longer-term changes in the structure of the Ningaloo aggregation.

We detected a well-supported relationship between dorsal fin height and total length (TL). Because this species cannot be restrained, it is preferable to measure dorsal fin height rather than TL in the field. Fin height could be estimated with relative ease and accuracy, compared with estimates of TL that were obtained by swimming measuring tapes alongside moving animals often metres below the surface. In the future, stereo cameras may provide a better approach for in situ measurements of whale shark dimensions. These systems can measure large animals accurately (e.g. tuna, Harvey et al. 2003) and at the same time could provide photographs for identification studies.

Individual identification demonstrated that some individuals remain at Ningaloo Reef for several months and return in successive years. A total of 59 individuals were resighted from the photographic databases. Of these, 46 were resighted during the same year they were initially photographed and 33 were resighted in different years. Overall, $73 \%$ of the resighted sharks were male and $17 \%$ were females, proportions that were similar to the sex ratios of the population. Resightings within the same year showed that some sharks could remain in the area of Ningaloo Reef for up to 4 mo. However, the majority of resightings in the same year were separated by only a few days or weeks. Of the sharks photographed in multiple years, the interval between resightings was typically 1 to $3 \mathrm{yr}$, although 3 individuals were resighted after $\geq 10 \mathrm{yr}$.

The photo-identification data provided estimates of population abundance at Ningaloo Reef. However, due to the small number of resighted individuals in the latter years of the study period, abundance estimates should be treated with caution. Based on the closed population models, the most realistic abundance estimate ranged from approximately 300 to 500 individuals. Relaxing the assumption of closure using openpopulation models provided a more-precise population size (319 to 436) for the full dataset. These estimates in combination with the lower estimates ( 150 to 250) for the 1992 to 1996 period estimated by the closedpopulation models suggest that the number sharks participating in the Ningaloo aggregation in any given year is perhaps somewhat smaller than the superpopulation comprised of individuals that visit the reef at some point during their lifetime. By comparison, only 40 sharks are thought to participate in the whale shark aggregation that occurs off Gladden Spit in Belize (Heyman et al. 2001, CITES 2002). However, anecdotal reports suggest that aggregations of whale sharks comparable in size or larger to that at Ningaloo Reef may occur at other sites in the Indian Ocean, 
notably off the coast of Gujurat in India (Pravin 2000) and in the Seychelles (D. Rowat, pers. comm.).

The large overlap in population estimates derived from the closed- and open-population models suggest that the super-population attending Ningaloo Reef does not consist of a completely transient subset of the Indian Ocean Rhincodon typus population, and this has potential implications for the conservation of this species. An ongoing tagging program has shown that many sharks disperse to the north towards Indonesia after leaving Ningaloo Reef (Wilson et al. 2006, M. G. Meekan et al. unpubl. data). In Indonesia, sharks are a major target of artisanal and commercial fisheries and it is likely that whale sharks are hunted in these waters as is the case in much of Southeast Asia (Eckert et al. 2002). If over-fishing is occurring in part of the range of the Ningaloo sharks, the observation that many individuals return to this aggregation suggests that any demographic effects of this process will be seen in the protected population at Ningaloo. Given the probable life-history traits of these animals (Colman 1997), any recovery of numbers once over-fishing has ceased would take many years.

For these reasons, it is imperative that migration pathways of whale sharks are established. Photoidentification will not be suitable for this task because there are relatively few sites in the Indian Ocean where photographic databases of whale sharks have been compiled (with the exception of the Seychelles and Maldive Islands). Comparison of photographs will show the amount of exchange in populations occurring at this spatial scale, but will not reveal migration routes. Satellite-tagging (Eckert \& Stewart 2001, Eckert et al. 2002) provides the most cost-effective means to investigate migratory behaviour (Fowler 2000).

A central requirement of the photo-identification technique is that distinctive markings and scars do not change over time. We found evidence to support this assumption because 2 sharks were identified in this manner from photographs taken at intervals of more than a decade. This suggests that these patterns possibly remain unchanged over the long term, and this has also been reported elsewhere (Arzoumanian et al. 2005). However, this may not be true for all individuals because both of these resighted sharks were approximately 7.5 m TL when photographed in 2003 and 2004 . It seems more likely that spot and stripe patterns might change as small (younger) sharks grow to larger sizes such as has been documented in leopard sharks Stegostoma fasciatum (Daley et al. 2002). For S. fasciatum, individual identification requires the use of a combination of the patterns on the dorsal surface and distinctive scars. In contrast, whale shark embryos have spot and stripe patterns remarkably similar in appearance to those of adults (Garrick 1964, Joung et al. 1996). Furthermore, nearly all whale sharks sighted at Ningaloo Reef were over $4 \mathrm{~m} \mathrm{TL}$, thus patterns on dorsal surfaces may have already undergone any major alterations that occur with growth. Nonetheless, our models' parameter estimates are entirely contingent on the assumption of long-term stability of the micro-patterns observed on the lateral area behind the last gill slit and the permanence of distinctive scars. If, for example, these patterns change over time, the number of resighted individuals would be underestimated and lead to an upward bias in population size. The advent of permanent marking techniques such as genetic 'tagging' (e.g. Feldheim et al. 2002, Mowat \& Paetkau 2002, Eggert et al. 2003) for whale sharks will permit validation of our model predictions.

Image quality was one of the principal factors influencing the speed of analysis and comparison of photographs. The use of underwater photography added a degree of difficulty not present in other photoidentification studies of marine megafauna that usually take photographs from the vantage points of planes, boats or from the shore (Würsig \& Jefferson 1990). Refraction of light on the lateral surface of the animal was a major problem in many photographs because it made it difficult to discern spot and line patterns. Additionally, snorkelling with camera gear in rough seas while photographing an animal that swims at a velocity of approximately 2 knots meant that selection of the correct angle and view of the shark was difficult. Equipment also influenced quality because images captured from digital videotape were generally much grainier and of poorer quality than those taken by still cameras.

Our study shows that photo-identification offers a practical, non-destructive means to obtain data on the population size and demography of whale sharks, but for the potential to be completely realized, standard techniques need to be applied to the collection of photographic databases. If this is done, the regular encounters with whale sharks offered to divers by the ecotourism industry in localities worldwide could provide a simple means to generate many photographs for analysis. For people who enjoy encountering these spectacular animals in their natural environment, and for those who base their livelihoods on the popularity of this experience, this offers the opportunity to contribute directly to the conservation and understanding of the ecology of whale sharks.

Acknowledgements. We thank J. Polovina for access to unpublished data on whale shark dorsal fin heights and total lengths. We acknowledge the support of the whale shark ecotourism industry based in Exmouth and Coral Bay, Western Australia. We thank the West Australian Department of Conservation and Land Management (CALM), particularly 
C. Simpson, J. Cary, R. Mau and B. Fitzpatrick. We thank 4 anonymous reviewers for helpful comments to improve the manuscript.

\section{LITERATURE CITED}

Akaike H (1973) Information theory as an extension of the maximum likelihood principle. In: Petrov BN, Csaki F (eds) Proceedings of the Second International Symposium on Information Theory. Budapest, Hungary, p 267-281

Arzoumanian Z, Holmberg J, Norman B (2005) An astronomical pattern-matching algorithm for computer-aided identification of whale sharks Rhincodon typus. J Appl Ecol 42:999-1011

Burnham KP, Anderson DR (2002) Model selection and multimodal inference: a practical information-theoretic approach. Springer-Verlag, New York

Castro ALF, Rosa RS (2005) Use of natural marks on population estimates of the nurse shark, Ginglymostoma cirratum, at Atol das Rocas Biological Reserve, Brazil. Environ Biol Fishes 72:213-221

Cerchio S (1998) Estimates of humpback whale abundance off Kauai, 1989-1993: evaluating biases associated with sampling the Hawaiian Islands breeding assemblage. Mar Ecol Prog Ser 175:23-24

Chaloupka M, Osmond M, Kaufman G (1999) Estimating seasonal abundance trends and survival probabilities of humpback whales in Hervey Bay (east coast of Australia). Mar Ecol Prog Ser 184:291-301

Chao A (1989) Estimating population size for sparse data in capture-recapture experiments. Biometrics 45:427-438

Chao A, Lee SM, Jeng SL (1992) Estimating population size for capture-recapture data when capture probabilities vary by time and individual animal. Biometrics 48: 201-216

Chen CT, Liu KM, Joung SJ (1997) Preliminary report on Taiwan's whale shark fishery. TRAFFIC Bull 17:53-57

CITES (Convention on International Trade in Endangered Species of Wild Fauna and Flora) (2002) Appendix II nomination of the whale shark, Rhincodon typus, proposal 12.35, 12th Meeting, Santiago, Chile. Available at: www.cites.org/eng/cop/12/prop/index.shtml

Colman JG (1997) A review of the biology and ecology of the whale shark. J Fish Biol 51:1219-1234

Daley RK, Stevens JD, Last PR, Yearsley GK (2002) Field guide to Australian sharks and rays. CSIRO Publishing, Melbourne

Darroch JN (1958) The multiple-recapture census: I. Estimation of a closed population. Biometrika 45:343-359

Davis D (1998) Whale shark tourism in Ningaloo Marine Park, Australia. Anthrozoos 11:5-11

Davis D, Banks S, Birtles A, Valentine P, Cuthill M (1997) Whale sharks in Ningaloo Marine Park - managing tourism in an Australian marine protected area. Tourism Manage 18:259-271

Eckert SA, Stewart BS (2001) Telemetry and satellite tracking of whale sharks, Rhincodon typus, in the Sea of Cortez, Mexico, and the north Pacific Ocean. Environ Biol Fishes 60:299-308

Eckert SA, Dolar LL, Kooyman GL, Perrin W, Rahman RA (2002) Movements of whale sharks (Rhincodon typus) in South-east Asian waters as determined by satellite telemetry. J Zool 257:111-115

Eggert LS, Eggert JA, Woodruff DS (2003) Estimating population sizes for elusive animals: the forest elephants of Kakum National Park, Ghana. Mol Ecol 12:1389-1402
Feldheim KA, Gruber SH, de Marignac JRC, Ashley MV (2002) Genetic tagging to determine passive integrated transponder tag loss in lemon sharks. J Fish Biol 61: 1309-1313

Fitzpatrick B, Meekan MG, Richards R (2006) Shark attacks on a whale shark (Rhincodon typus Smith 1828) at Ningaloo Reef, Western Australia. Bull Mar Sci 78:397-402

Forcada J, Hammond PS, Aguilar A (1999) Status of the Mediterranean monk seal Monachus monachus in the western Sahara and the implications of a mass mortality event. Mar Ecol Prog Ser 188:249-261

Fowler SL (2000) Whale shark Rhincodon typus. Policy and research scoping study. Nature Conservation Bureau, Newbury

Garrick JAF (1964) Additional information on the morphology of an embryo whale shark. Proc US Nat Mus 115:1-8

Hamilton PK, Knowlton AR, Marx MK, Kraus SD (1998) Age structure and longevity in North Atlantic right whales Eubalaena glacialis and their relation to reproduction. Mar Ecol Prog Ser 171:285-292

Harvey E, Cappo M, Shortis M, Robson S, Buchanan J, Speare $\mathrm{P}$ (2003) The accuracy and precision of underwater measurements of length and maximum body depth of southern blue fin tuna (Thunnus maccoyii) with a stereo-video camera system. Fish Res 63:315-326

Heithaus MR (2001) The biology of tiger sharks, Galeocerdo cuvier, in Shark Bay, Western Australia: sex ratio, size distribution, diet and seasonal changes in catch rates. Environ Biol Fishes 61:25-36

Heyman WD, Graham RT, Kjerfve B, Johannes RE (2001) Whale sharks Rhincodon typus aggregate to feed on fish spawn in Belize. Mar Ecol Prog Ser 215:275-282

Joung SJ, Chen CT, Clark E, Uchida S, Huang WYP (1996) The whale shark, Rhincodon typus, is a livebearer-300 embryos found in one megamamma supreme. Environ Biol Fishes 46:219-223

Kendall WL, Hines JE, Nichols JD (2003) Adjusting multistate capture-recapture models for misclassification bias: manatee breeding proportions. Ecology 84:1058-1066

Klimley AP (1987) The determinants of sexual segregation in the scalloped hammerhead shark, Sphyrna lewini. Environ Biol Fishes 18:27-40

Koski WR, Davis RA, Miller GW, Withrow DE (1992) Growth rates of bowhead whales as determined from low-level aerial photogrammetry. Rep Int Whal Comm 42:491-499

Lebreton JD, Burnham KP, Clobert J, Anderson DR (1992) Modeling survival and testing biological hypotheses using marked animals: a unified approach with case studies. Ecol Monogr 62:67-118

Mizroch SA, Herman LM, Straley JM, Glockner-Ferrari DA and 6 others (2004) Estimating the adult survival rate of central North Pacific humpback whales (Megaptera novaeangliae). J Mammal 85:963-972

Mowat G, Paetkau D (2002) Estimating marten Martes americana population size using hair capture and genetic tagging. Wildl Biol 8:201-209

Nichols JD (1992) Capture-recapture models: using marked animals to study population dynamics. Bioscience 42: 94-102

Otis DL, Burnham KP, White GC (1978) Statistical inference for capture data on closed animal populations. Wildl Monogr 62:1-135

Pratt H (1979) Reproduction in the blue shark, Prionace glauca. Fish Bull 77:445-470

Pravin P (2000) Whale shark in the Indian coast-need for conservation. Current Sci 79:310-315

Schwarz CJ, Arnason AN (1996) A general methodology 
for the analysis of open-model capture recapture experiments. Biometrics 52:860-873

Sims DW, Nash JP, Morritt D (2001) Movements and activity of male and female dogfish in a tidal sea lough: alternative behavioural strategies and apparent sexual segregation. Mar Biol 139:1165-1175

Sokal RR, Rohlf FJ (1981) Biometry. The principles and practice of statistics in biological research. WH Freeman, New York

Springer S (1967) Social organisation of shark populations. In: Gilbert PW, Mathewson RF, Rall DP (eds) Sharks, skates and rays. Johns Hopkins Press, Baltimore, MD, p 149-174

Stevick PT, Palsbøll PJ, Smith TD, Bravington MV, Hammond PS (2001) Errors in identification using natural markings: rates, sources, and effects on capture-recapture estimates of abundance. Can J Fish Aquat Sci 58:1861-1870

Taylor G (1994) Whale sharks. Angus \& Robertson Publishers, Sydney

Taylor JG (1996) Seasonal occurrence, distribution and move-

Editorial responsibility: Otto Kinne (Editor-in-Chief), Oldendorf/Luhe, Germany ments of the whale shark, Rhincodon typus, at Ningaloo Reef, Western Australia. Mar Freshw Res 47:637-642

White GC, Burnham KP (1999) Program MARK: survival estimation from populations of marked animals. Bird Stud 46 (Suppl):120-138

Wilson S (2004) Basking sharks (Cetorhinus maximus) schooling in the southern Gulf of Maine. Fish Oceanogr 13:283-286

Wilson SG, Taylor JG, Pearce AF (2001) The seasonal aggregation of whale sharks at Ningaloo reef, western Australia: currents, migrations and the El Nino/Southern oscillation. Environ Biol Fishes 61:1-11

Wilson SG, Polovina JJ, Steward BS, Meekan MG (2006) Movements of whale sharks (Rhincodon typus) tagged at Ningaloo Reef, Western Australia. Mar Biol 148:1157-1166

Wintner SP (2000) Preliminary study of vertebral growth rings in the whale shark, Rhincodon typus, from the east coast of South Africa. Environ Biol Fishes 59:441-451

Würsig B, Jefferson T (1990) Methods of photo-identification for small cetaceans. Rep Int Whal Comm 12:43-52

Submitted: December 15, 2004; Accepted: December 29, 2005 Proofs received from author(s): July 24, 2006 